\title{
Non-culture-based identification of mastitis-causing bacteria by MALDI-TOF mass spectrometry
}

\author{
Juliana Regina Barreiro, ${ }^{*}$ Juliano Leonel Gonçalves, ${ }^{*}$ Patrícia Aparecida Campos Braga, $\dagger$ \\ Aline Gerato Dibbern, ${ }^{*}$ Marcos Nogueira Eberlin, $†$ and Marcos Veiga dos Santos ${ }^{* 1}$ \\ *Department of Animal Sciences, School of Veterinary Medicine and Animal Sciences, University of São Paulo, Pirassununga, SP, Brazil, \\ $13.635-900$ \\ †ThoMSon Mass Spectrometry Laboratory, Institute of Chemistry, University of Campinas (UNICAMP), Campinas, SP, Brazil, 13.083-970
}

\section{ABSTRACT}

The purpose of this study was to evaluate the detection limit of matrix-assisted laser desorption/ ionization time-of-flight mass spectrometry (MALDITOF MS) for direct identification, without previous microbiological culture, of bovine mastitis-causing bacteria from milk samples. Milk samples $(\mathrm{n}=15)$ were experimentally contaminated with Staphylococcus aureus, Streptococcus uberis, Streptococcus agalactiae, Streptococcus dysgalactiae, and Escherichia coli to have bacterial counts ranging from $10^{3}$ to $10^{9} \mathrm{cfu} / \mathrm{mL}$. These contaminated milk samples were subjected to a preparation protocol for bacterial ribosomal protein extraction using the MALDI Sepsityper kit (Bruker Daltonik, Bremen, Germany), which allowed MALDI-TOF MS coupled with Biotyper software (Bruker Daltonik) to identify bacterial fingerprints based on intact ribosomal proteins. The ability of MALDI-TOF MS to correctly identify bacterial strains from experimentally contaminated milk (without previous microbiological culture) depended on the bacterial count of the samples and on the species of the bacteria evaluated. Adequate identification at the bacterial species level (score $\geq 2.0$ ) directly from milk samples required bacterial counts in the following ranges: $\geq 10^{6} \mathrm{cfu} / \mathrm{mL}$ of Staph. aureus, $\geq 10^{7} \mathrm{cfu} / \mathrm{mL}$ of $E$. coli, and $\geq 10^{8} \mathrm{cfu} / \mathrm{mL}$ of Strep. agalactiae, Strep. dysgalactiae, and Strep. uberis. We concluded that direct identification of mastitis-causing pathogens is possible for Staph. aureus, E. coli, Strep. agalactiae, Strep. dysgalactiae, and Strep. uberis, but correct identification depended on the bacterial count in the milk samples.

Key words: milk, bacteria, mastitis, MALDI-TOF mass spectrometry

Received July 15, 2016.

Accepted November 22, 2016.

${ }^{1}$ Corresponding author: mveiga@usp.br

\section{INTRODUCTION}

In subclinical mastitis, the most common form of mastitis in dairy cattle (Malek dos Reis et al., 2011), no signs of abnormality are visible in the milk or udder, but milk yield and quality are reduced (Hovinen and Pyörälä, 2011). During episodes of subclinical mastitis, SCC increases, and concentrations of milk components (casein, milk fat, lactose, minerals, and enzymes) are altered. These alterations in milk composition are associated with decreased secretion of milk components and increased vascular permeability in the mammary gland (Pyörälä, 2003), resulting in negative effects on milk yield and quality (Santos et al., 2003).

Routine methods for indirectly diagnosing subclinical mastitis and assessing milk quality are based on evaluation of SCC in composite milk samples, or on detection of biochemical changes in milk. The cause of intramammary infection is identified using microbiological culture or molecular biology. The routine identification of mastitis-causing microorganisms depends mainly on phenotypic characteristics such as colony morphology, hemolytic potential, and biochemical reactions (Viguier et al., 2009). Rapid and correct diagnosis of the causative agents of mastitis is important for the selection of specific treatment protocols and methods of control (Pankey et al., 1991).

Methods for microorganism identification based on colony growth in bacterial culture medium or biochemical tests have remained unaltered for some time. However, over the last decade, DNA-based assays, mainly those based on PCR or 16S rRNA gene sequencing, have been evaluated for their ability to overcome some of the limitations of traditional phenotypic procedures; however, these methods are also time-consuming and laborious (Rajendhran and Gunasekaran, 2011).

Matrix-assisted laser desorption/ionization time-offlight mass spectrometry (MALDI-TOF MS) can be used for the rapid identification of bacterial species in biological samples (Seng et al., 2009; Seng et al., 2010) and in bacterial isolates from milk samples of 
cows with subclinical mastitis (Gonçalves et al., 2014; Tomazi, et al., 2014). This method is based on the acquisition of protein (ribosomal proteins) "fingerprints" directly from intact microorganisms, because such profiles vary considerably among microorganisms. The MALDI-TOF technique has been incorporated into diagnostic routines for human and veterinary clinical microbiology, because it allows for database searching and precise identification, and it is highly reproducible (Bizzini and Greub, 2010; Seng et al., 2010). As well, the MALDI-TOF MS methodology is faster than conventional microbiological culture and DNA techniques for identification of microorganisms in clinical samples (Fenselau and Demirev, 2001; Ilina et al., 2009).

The MALDI-TOF MS method has been used for the rapid diagnosis of bacterial species directly from human blood samples, without previous culture, but the total bacterial count of the sample was a limiting factor for successful identification (Moussaoui et al., 2010). It has also allowed direct identification of microorganisms in urine and cerebrospinal fluid samples (Ferreira et al., 2010; Segawa et al., 2014). However, the use of MALDITOF MS has not been fully explored for all pathogens or in mastitic milk (Barreiro et al., 2012). The rapid identification of mastitis-causing pathogens may allow for disease monitoring in dairy herds, more appropriate treatment protocols based on the mastitis-causing pathogen, or the adoption of other control procedures (segregation, culling, and anticipated drying off of infected cows).

The present study aimed at determining the detection limit of MALDI-TOF MS for the direct identification (without previous microbiological culture) of mastitis-causing bacteria (Staphylococcus aureus, Streptococcus uberis, Streptococcus agalactiae, Streptococcus dysgalactiae, and Escherichia coli) from experimentally contaminated milk samples.

\section{MATERIALS AND METHODS}

\section{In Vitro Contamination of Milk Samples}

Milk was experimentally contaminated using 5 bacterial strains of the genera and species that can cause bovine mastitis, including Staph. aureus ATCC 29213, Strep. uberis DSM 20569, Strep. agalactiae ATCC 13813, Strep. dysgalactiae DSM 20662, and E. coli ATCC 25922, 3 repetitions per strain, totaling 15 samples.

All bacterial strains were incubated at $37^{\circ} \mathrm{C}$ under aerobic conditions for growth using a blood agar plate that contained $5 \%$ defibrinated bovine blood. After 24 $\mathrm{h}$ of incubation at $37^{\circ} \mathrm{C}$, the colonies of each bacterial isolate were removed from the agar plates using a sterile flexible plastic loop $(10-\mu \mathrm{L}$ capacity) and carefully diluted in $2 \mathrm{~mL}$ of distilled water. The bacterial concentration in distilled water was estimated using the number 5 of the McFarland nephelometer scale (Nefelobac; Probac, São Paulo, Brazil). After turbidity standardization with distilled water, we obtained an estimated total bacterial count of $10^{9} \mathrm{cfu} / \mathrm{mL}$ was obtained, and 7 decimal serial dilutions were performed to obtain diluted samples from each bacterial strain with estimated total bacterial counts of $10^{3}$ to $10^{9} \mathrm{cfu} / \mathrm{mL}$ $(\mathrm{n}=105)$. Diluted samples were centrifuged, and the supernatant was discarded and the pellet resuspended in $2.0 \mathrm{~mL}$ sterile distilled water, which was then transferred to a $2.0 \mathrm{~mL}$ sterile microtube.

The skim milk for the bacterial decimal dilutions was prepared from powdered milk (Molico Nestle, São Paulo, Brazil), which was suspended in distilled water (1,000 $\mathrm{mL}$ of distilled water to $100 \mathrm{~g}$ of powdered milk) and autoclaved. Then, $1.0 \mathrm{~mL}$ of skim milk was added to each microtube containing the diluted bacterial pellet $\left(10^{3}\right.$ to $\left.10^{9} \mathrm{cfu} / \mathrm{mL}\right)$.

\section{MALDI-TOF MS Sample Preparation}

Procedures for direct identification of bacterial isolates by MALDI-TOF MS without previous microbiology culture were based on bacteria identification in human blood samples (Moussaoui et al., 2010). All centrifugation steps were performed at $13,000 \times g$ for 2 min.

The milk samples with inoculated bacteria $(1.0 \mathrm{~mL})$ were washed and prepared using a MALDI Sepsityper kit (Bruker Daltonik, Bremen, Germany), with the addition of $200 \mathrm{~mL}$ of lysis buffer solution. A sample of non-inoculated powdered skim milk was included as a control. Samples were centrifuged and the supernatant discarded using a $1,000-\mu \mathrm{L}$ pipette. After pellet formation, $1.0 \mathrm{~mL}$ of distilled water and $200 \mu \mathrm{L}$ of lysis buffer solution were added and carefully mixed with the bacterial pellet, followed by a second centrifugation step. The supernatant was discarded using a pipette, and 1.0 $\mathrm{mL}$ of a washing buffer solution was added, followed by a third centrifugation step. The supernatant was again discarded, so only the pellet remained in the tube.

Next, we used the bacterial lysis protocol for MALDITOF MS analysis described by Barreiro et al. (2012). The final bacterial pellet obtained was diluted in 1,200 $\mu \mathrm{L}$ of $75 \%$ ethanol solution $(300 \mu \mathrm{L}$ of deionized water and $900 \mu \mathrm{L}$ of ethanol) for bacterial inactivation. The bacterial sediment was centrifuged and the supernatant discarded by tube inversion. After that, another centrifugation step was performed to remove any residual ethanol, and the supernatant was removed using a pipette. After the pellet was dried at room temperature, 
a sufficient quantity of $70 \%$ formic acid solution was added to cover the pellet $(\sim 30-50 \mu \mathrm{L})$ and lyse the bacterial cells. After homogenization of the contents, the same volume $(\sim 30-50 \mu \mathrm{L})$ of $100 \%$ acetonitrile was added. During the final stage, centrifugation was performed to separate the bacterial cell sediments from the supernatant that contained the ribosomal bacterial proteins (Ryzhov and Fenselau, 2001), from which the MALDI-TOF mass spectra were obtained for bacterial identification.

A volume of $1.0 \mu \mathrm{L}$ of the bacterial extract was placed on a steel plate (mtp 384 Target Polished Steel; Bruker Daltonik, Bremen, Germany) for drying at room temperature $\left(20^{\circ} \mathrm{C}\right)$. The dried supernatant was overlaid with $1 \mu \mathrm{L}$ of matrix solution that consisted of Q-cyano-4-hydroxy-cinnamic acid diluted in 50\% acetonitrile and $2.5 \%$ trifluoroacetic acid. The mass spectrometer used was an Autoflex III (Bruker Daltonik, Billerica, MA). Mass spectra were collected in the $m / z$ 2,000-20,000 mass ranges.

The spectra obtained were analyzed using MALDI Biotyper 3.0 software (Bruker Daltonik, Bremen, Germany), which has over 4,000 referential spectra for microorganism identification (Dubois et al., 2010; Ilina et al., 2010). For clustering and creation of a genealogical tree, Biotyper allows similarity calculation of every spectrum obtained, using a pattern-matching library (Maier et al., 2010). Biotyper also provides the means of a log (score) between zero (no homology) and a maximum value of 3.0 (100\% homology). Scores $\geq 1.7$ were considered to be reliable genus identifications, and scores $\geq 2.0$ were considered to be reliable genus and species identifications (Nagy et al., 2009).

We evaluated the MALDI-TOF spectra obtained from the ATCC strains (Staph. aureus, Strep. uberis, Strep. agalactiae, Strep. dysgalactiae, and E. coli) after routine bacterial growth and compared the results with those from when the same isolates were suspended in skim milk and the MALDI Sepsityper kit was applied. The type strains were also submitted to the colony extraction protocol and analyzed using MALDI-TOF
MS as described by Barreiro et al. (2010). Briefly, to prepare the samples for MALDI-TOF MS, the bacterial strains were cultured for $24 \mathrm{~h}$ in a brain-heart infusion broth. The bacterial culture was centrifuged, inactivated in $75 \%$ ethanol, and submitted to bacterial extraction. With this protocol, the microtube containing isolated bacteria in $75 \%$ ethanol solution was centrifuged, and the supernatant was removed by carefully pouring it from the microtube. A second centrifugation step was performed, and the remaining liquid was carefully removed with a pipette tip. Bacterial pellets were allowed to air dry at room temperature for 5 to 10 min. A solution of $70 \%$ formic acid was added to lyse bacterial cells and release the ribosomal proteins that produce diagnostic ions in MALDI fingerprinting. A $70 \%$ formic acid solution was added proportionally to the size of pellet, to completely dissolve it. Then, $100 \%$ acetonitrile was added to each sample in volumes equal to the $70 \%$ formic acid solution added, producing a bacterial extract in a 1:1 ratio of $70 \%$ formic acid and acetonitrile. A final centrifugation step was performed to separate bacterial cell debris from the supernatant containing the ribosomal proteins used for the MALDITOF MS identification. After extraction, samples were run on the MALDI Biotyper as previously described.

\section{RESULTS}

The MALDI-TOF MS technique directly identified 5 strains of bacteria that can cause bovine mastitis (Staph. aureus, Strep. uberis, Strep. agalactiae, Strep. dysgalactiae, and E. coli) in experimentally contaminated milk, without previous culture. However, the score identification of the Biotyper program for direct identification from milk depended on the total bacterial count of the samples and on the type of bacteria assessed. For adequate identification at the species level (score $\geq 2.0$ ) directly from the milk, a bacterial count of $\geq 10^{6} \mathrm{cfu} / \mathrm{mL}$ was necessary for Staph. aureus, $\geq 10^{7} \mathrm{cfu} /$ $\mathrm{mL}$ for E. coli, and $\geq 10^{8} \mathrm{cfu} / \mathrm{mL}$ for Strep. agalactiae, Strep. dysgalactiae, and Strep. uberis (Tables 1 and 2).

Table 1. Mean identification scores $( \pm \mathrm{SE}$ ) distributed among decimal serial dilutions of mastitis-causing agents, according to bacterial count, obtained by the Biotyper ${ }^{1}$ program $(0=$ no identification $)$

\begin{tabular}{lcccccrr}
\hline & \multicolumn{9}{c}{ Dilutions (cfu/mL) } \\
\cline { 2 - 8 } Microorganism & $10^{3}$ & $10^{4}$ & $10^{5}$ & $10^{6}$ & $10^{7}$ & $10^{8}$ \\
\hline Escherichia coli & 0 & 0 & 0 & $1.658 \pm 0.05$ & $2.054 \pm 0.03$ & $2.47 \pm 0.02$ & $2.478 \pm 0.01$ \\
Staphylococcus aureus & 0 & $1.569 \pm 0.03$ & $1.796 \pm 0.01$ & $2.04 \pm 0.02$ & $2.185 \pm 0.09$ & $2.221 \pm 0.15$ & $2.205 \pm 0.12$ \\
Streptococcus agalactiae & 0 & 0 & 0 & $1.501 \pm 0.02$ & $1.902 \pm 0.05$ & $2.051 \pm 0.03$ & $2.144 \pm 0.03$ \\
Streptococcus dysgalactiae & 0 & 0 & 0 & $1.489 \pm 0.01$ & $1.726 \pm 0.01$ & $2.06 \pm 0.02$ & $2.131 \pm 0.03$ \\
Streptococcus uberis & 0 & 0 & 0 & $1.755 \pm 0.02$ & $1.889 \pm 0.01$ & $2.067 \pm 0.03$ & $2.119 \pm 0.05$ \\
\hline
\end{tabular}

${ }^{1}$ Bruker Daltonik, Bremen, Germany. 
Table 2. Results from the Biotyper ${ }^{1}$ program after collection and mass spectra processing based on inoculated bacteria in powdered skim milk samples

\begin{tabular}{llll}
\hline Analyte name $^{2}$ & Organism (best match) & Score & Organism (second-best match) \\
\hline Escherichia coli $10^{7}(++\mathrm{A})$ & Escherichia coli & 2.144 & Escherichia coli \\
Staphylococcus aureus $10^{6}(++\mathrm{A})$ & Staphylococcus aureus & 2.028 & Staphylococcus aureus \\
Staphylococcus aureus $10^{8}(++\mathrm{A})$ & Staphylococcus aureus & 2.119 & Staphylococcus aureus \\
Streptococcus agalactiae $10^{8}(++\mathrm{A})$ & Streptococcus agalactiae & 2.051 & Streptococcus agalactiae \\
Streptococcus dysgalactiae $10^{8}(++\mathrm{C})$ & Streptococcus dysgalactiae & 2.06 & Lactobacillus alimentarius \\
Streptococcus uberis $10^{8}(+\mathrm{B})$ & Streptococcus uberis & 2.02 & Streptococcus uberis \\
\hline
\end{tabular}

${ }^{1}$ Bruker Daltonik, Bremen, Germany.

${ }^{2}+=$ probable genus identification; $++=$ secure genus identification, probable species identification; $\mathrm{A}=$ species consistency; $\mathrm{B}=$ genus consistency; $\mathrm{C}=$ neither genus nor species consistency.

The quality of the acquired spectra by MALDI-TOF depended on the initial count of the bacteria present in the milk samples (Figures 1 and 2). When comparing the spectra acquired in the range of 2,000 to $12,000 \mathrm{Da}$ from the non-culture-based identification protocol with those obtained from the colony extraction protocol, we observed that the spectra obtained from the colony extraction protocol presented higher score identification considering the protein peaks (Figures 1 and 2). On the other hand, the spectra obtained directly from milk presented a variety of fields with unsatisfactory signalto-noise spectra, showing that other compounds were present (Figure 2g).

\section{DISCUSSION}

Using microbiological culture, diagnosis at the species level of agents causing bovine mastitis takes an average of 2 to $7 \mathrm{~d}$, which could delay the application of control and treatment procedures. We evaluated a non-culture diagnostic method for mastitis-causing bacteria in milk samples using MALDI-TOF MS.

To assess the proposed methodology, we adapted a protocol used to directly detect bacteria in human blood, modifying it to process samples of milk (Moussaoui et al., 2010). The MALDI-TOF technique was able to correctly identify, at the bacterial spe-

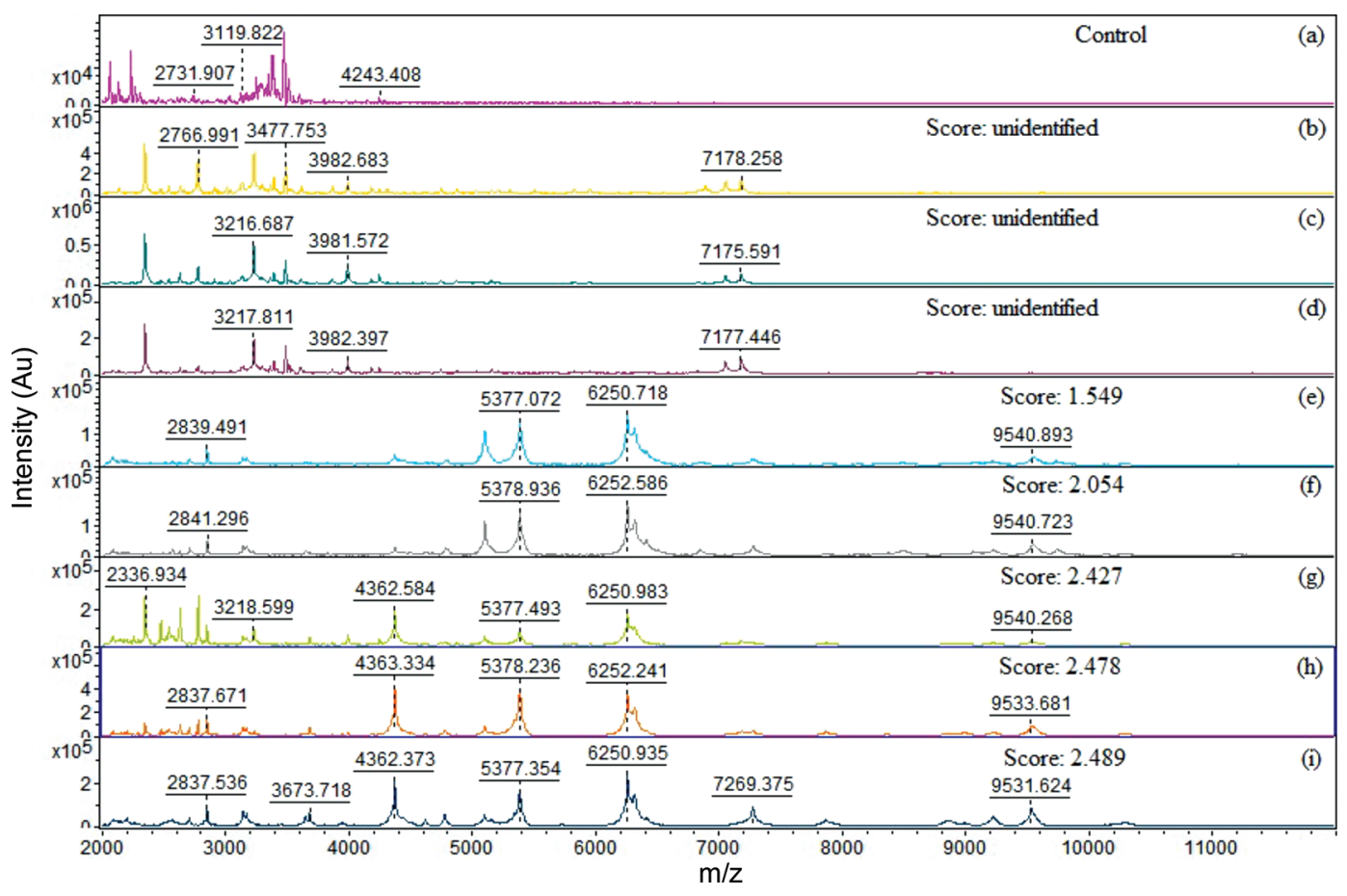

Figure 1. Matrix-assisted laser desorption/ionization time-of-flight mass spectrometry: Spectra in the range of 2,000 to $12,000 \mathrm{~m} / z$, acquired during experimental assays with milk: (a) Control (powder skim milk sample without inoculated bacteria); (b) $10^{3}$, (c) $10^{4}$, (d) $10^{5}$, (e) $10^{6}$, (f) $10^{7},(\mathrm{~g}) 10^{8},(\mathrm{~h}) 10^{9}$ of Escherichia coli cfu/mL; and (i) the spectra of a pure ATCC 25922 (American Type Culture Collection) Escherichia coli colony. Color version available online. 


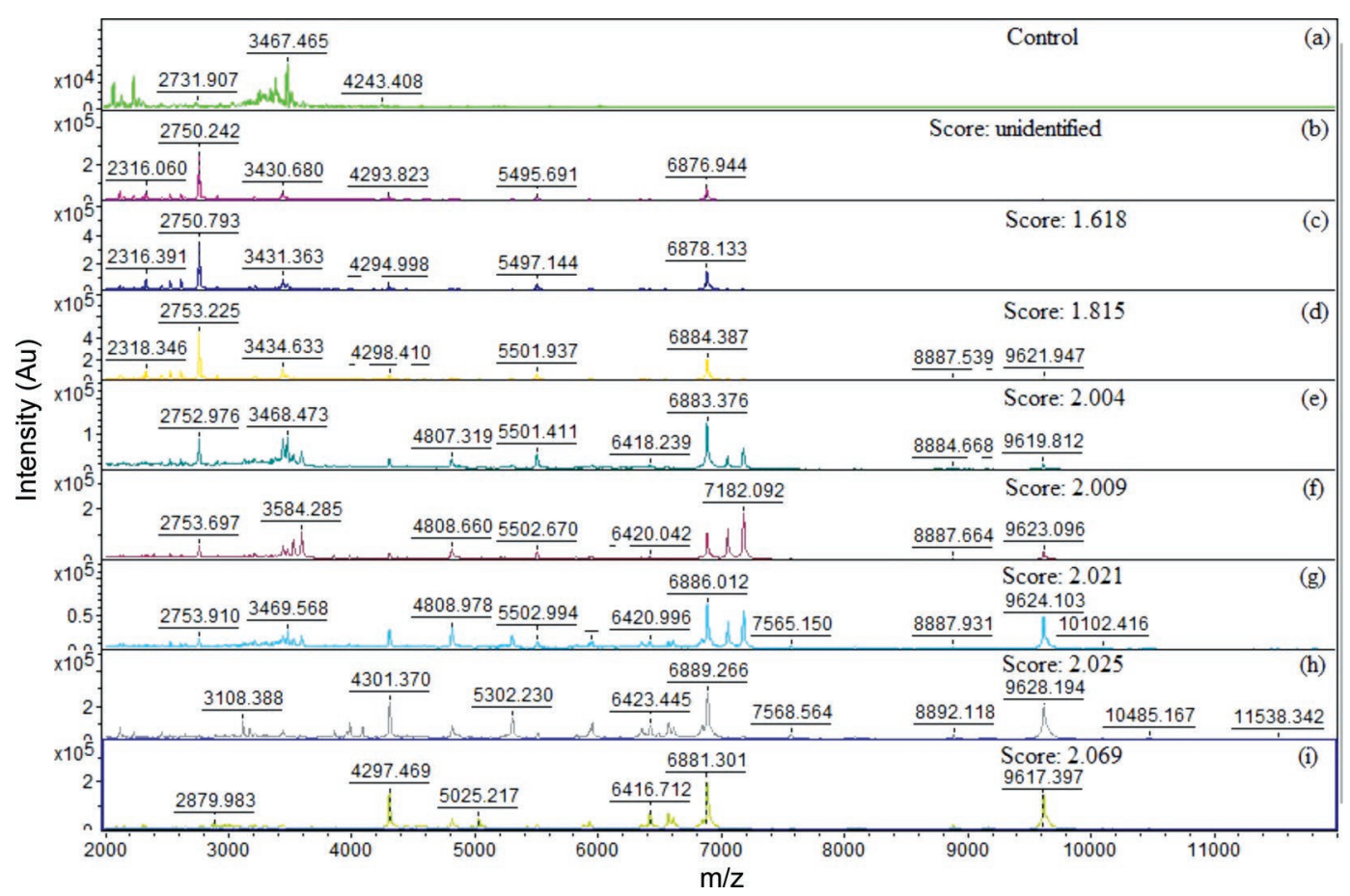

Figure 2. Matrix-assisted laser desorption/ionization time-of-flight mass spectrometry: Spectra in the range of 2,000 to $12,000 \mathrm{~m} / z$, acquired during experimental assays with milk: (a) Control (powder skim milk sample without inoculated bacteria); (b) $10^{3}$, (c) $10^{4}$, (d) $10^{5}$, (e) $10^{6}$, (f) $10^{7}$, (g) $10^{8}$, (h) $10^{9}$ of Staphylococcus aureus cfu/mL; and (i) the spectra of a pure ATCC 29213 (American Type Culture Collection) Staphylococcus aureus colony. Color version available online.

cies level, samples experimentally contaminated with Staph. aureus, Strep. uberis, Strep. agalactiae, Strep. dysgalactiae, and E. coli, directly from milk. However, the detection limit of MALDI-TOF MS depended on the bacterial count in the milk sample. This result is similar to those described for the direct identification of microorganisms in human blood (Moussaoui et al., 2010). Indeed, Szabados et al. (2010) suggested that the bacterial count of human blood samples should be $>10^{7} \mathrm{cfu} / \mathrm{mL}$ to achieve the correct direct identification of bacteria from positive blood culture bottles.

The detection limit (i.e., the lower detection of a pathogen using a given diagnostic method) is the smallest quantity of an infectious agent detected using the method in evaluation, and the ability to distinguish it from a negative result. To determine the detection limit of a diagnostic assay, dilutions are used until the method is no longer able to detect the target in question (Office International des Épizooties, 2010). In this study, the detection limit for the direct identification of mastitis-causing pathogens was based on analysis of a series of 7 decimal dilutions $\left(10^{3}\right.$ to $\left.10^{9} \mathrm{cfu} / \mathrm{mL}\right)$ of the 5 pathogens isolated from milk samples. Diluted and experimentally contaminated milk samples were submitted to an extraction protocol and analyzed by MALDI-TOF MS, which indicated that detection limit was of $\geq 10^{6} \mathrm{cfu} / \mathrm{mL}$ for Staph. aureus, $\geq 10^{7} \mathrm{cfu} / \mathrm{mL}$ for E. coli, and $\geq 10^{8} \mathrm{cfu} / \mathrm{mL}$ for Strep. agalactiae, Strep. dysgalactiae, and Strep. uberis, to obtain a score $\geq 2.0$, which would indicate the correct identification at the bacterial species level. These results are similar to those described by Barreiro et al. (2012), in which the minimum bacterial count for the diagnosis of the pathogen present in milk samples was of $10^{6} \mathrm{cfu} / \mathrm{mL}$ and $10^{7} \mathrm{cfu} /$ $\mathrm{mL}$ for Staph. aureus and E. coli, respectively.

In the present study, identification at the genus level (score $\geq 1.7$ ) of Staph. aureus was possible at a bacterial count of $\geq 10^{5} \mathrm{cfu} / \mathrm{mL}, E$. coli at a bacterial count of $\geq 10^{6} \mathrm{cfu} / \mathrm{mL}$, and Strep. agalactiae, Strep. dysgalactiae and Strep. uberis at a bacterial count of $\geq 10^{7} \mathrm{cfu} /$ mL. Stevenson et al. (2010) evaluated 14 human blood samples that were culture-positive for Staph. aureus and reported scores of $<1.7$ in 2 cases $(14.3 \%)$ and 1.7 to 1.9 in 3 cases (21.4\%). In 9 blood cultures, Staph. aureus was correctly identified $(64.3 \%$, scores $\geq 2.0)$. Ferreira et al. (2011) identified Staph. aureus at the species level in only 2 of 36 samples (5.5\%), and at the genus level in 11 of $36(30.6 \%)$ in cultures from human blood samples.

In studies using MALDI-TOF to identify yeast in blood cultures, a yeast suspension adjusted to the McFarland standard (approximately $10^{7} \mathrm{cfu} / \mathrm{mL}$ ) was 
used (Bidart et al., 2015). These authors proposed that the interpretation thresholds may be adapted. In this way, the identification scores were reclassified into 4 categories: $>2 ; 1.7$ to $2 ; 1.4$ to 1.7 , if the same species appeared 4 times as a result suggestion; $<1.4$ or unidentified. The threshold of scores $>2$ was acceptable for identification at the species level, and the assays resulted in correct identification 94/115 (81.7\%) samples, according to the adapted scores using the Sepsityper kit (Bidart et al., 2015). Therefore, an adjustment of the identification score of mastitis-causing pathogens directly in milk samples is necessary; a correct identification score could be between 1.7 and 2 .

We observed that the MALDI-TOF detection capacity of the pathogens might be different depending on the bacterial species, as described by Moussaoui et al. (2010). The MALDI-TOF MS technique has been used successfully to identify mastitis-causing pathogens from bacterial colonies on agar plates (Barreiro et al., 2010), but it still depends on initial microbiological culture, which is time-consuming and laborious (i.e., plate preparation, sterilization of materials, time of incubation, biochemistry tests). We evaluated non-culture-based identification of mastitis-causing bacteria using MALDI-TOF, aiming to avoid these initial microbiological culture steps.

On the other hand, initial investment in MALDITOF equipment is expensive. Additionally, our study was limited by the fact that the evaluated protocol may work for only a limited number of mastitic milk samples, mainly those with high counts of a single pathogen. The results of the present study may represent a contribution to future studies on MALDI-TOF protocols for the identification of mastitis-causing pathogens. For example, the non-culture-based protocol could be applied in diagnostic laboratories by subjecting all milk samples to direct MALDI-TOF, and those without a positive identification could be submitted to a 4 -h preincubation protocol, being identified by MALDI-TOF MS combined with standard bacteriology. This incubation protocol could be necessary to increase the number of mastitis pathogens identified. The minimum number of colonies cultured for diagnosing quarters with IMI varied from 100 to $1,000 \mathrm{cfu} / \mathrm{mL}$ (Dohoo et al., 2011), lower than the detection limit of the non-culture-based MALDI-TOF approach $\left(\geq 10^{6}\right.$ to $\left.\geq 10^{8} \mathrm{cfu} / \mathrm{mL}\right)$.

In the present study, non-culture-based MALDI-TOF was capable of identifying 5 bacterial strains that can cause bovine mastitis at a certain minimum number of colonies. However, it is not known how this technique would perform in mastitic milk samples. Our results suggest that milk introduces unsatisfactory signal-tonoise spectra, and this may be further exacerbated by inflammation or coinfection in milk samples. We ini- tially proposed to evaluate total bacterial count, asking what number of colonies would be necessary to obtain a score identification at the species level by MALDITOF MS using powered skim milk and whether the total bacterial count would change depending on the mastitis-causing pathogen.

Overall, pathogen identification by direct analysis of milk may provide rapid identification, but the bacterial count in the sample directly affects the ability of MALDI-TOF to correctly identify the bacteria.

\section{CONCLUSIONS}

The MALDI-TOF MS technique was able to identify bacterial strains of the genus and species that cause bovine mastitis in experimentally inoculated milk samples, without the need for previous culture, when the samples presented bacterial counts of $\geq 10^{6} \mathrm{cfu} / \mathrm{mL}$ for Staph. aureus, $\geq 10^{7} \mathrm{cfu} / \mathrm{mL}$ for E. coli, and $\geq 10^{8}$ $\mathrm{cfu} / \mathrm{mL}$ for Strep. agalactiae, Strep. dysgalactiae, and Strep. uberis.

\section{ACKNOWLEDGMENTS}

We are grateful to the Fundação de Amparo à Pesquisa do Estado de São Paulo (FAPESP), Brazil, for a scholarship award (2011/14456-0) and research funding $(2011 / 15815-4)$.

\section{REFERENCES}

Barreiro, J. R., C. R. Ferreira, P. A. C. Braga, M. Kostrzewa, T. Maier, B. Wegemann, V. Böettcher, M. N. Eberlin, and M. V. Santos. 2012. Nonculture-based identification of bacteria in milk by protein fingerprinting. Proteomics 12:2739-2745.

Barreiro, J. R., C. R. Ferreira, M. Kostrzewa, T. Maier, B. Wegemann, V. Böettcher, M. N. Eberlin, and M. V. Santos. 2010. Rapid and comprehensive identification of subclinical cow mastitis pathogens in milk by MALDI-TOF mass spectrometry. J. Dairy Sci. 93:5661-5667.

Bidart, M., I. Bonnet, A. Hennebique, Z. E. Kherraf, H. Pelloux, F. Berger, M. Cornet, S. Bailly, and D. Maubon. 2015. An in-house assay is superior to Sepsityper for direct matrix-assisted laser desorption ionization-time of flight (MALDI-TOF) mass spectrometry identification of yeast species in blood cultures. J. Clin. Microbiol. 53:1761-1764.

Bizzini, A., and G. Greub. 2010. Matrix-assisted laser desorption ionization time-of-flight mass spectrometry, a revolution in clinical microbial identification. Clin. Microbiol. Infect. 16:1614-1619.

Dohoo, I. R., J. Smith, S. Andersen, D. F. Kelton, and S. Godden. 2011. Diagnosing intramammary infections: Evaluation of definitions based on a single milk sample. J. Dairy Sci. 94:250-261.

Dubois, D., D. Leyssene, J. P. Chacornac, M. Kostrzewa, P. O. Schmit, R. Talon, R. Bonnet, and J. Delmas. 2010. Identification of a variety of Staphylococcus species by matrix-assisted laser desorption ionization-time of flight mass spectrometry. J. Clin. Microbiol. 48:941-945.

Fenselau, C., and P. A. Demirev. 2001. Characterization of intact microorganism by MALDI mass spectrometry. Mass Spectrom. Rev. 20:157-171. 
Ferreira, L., F. Sánchez-Juanes, M. González-Ávila, D. CembreroFucinos, A. Herrero-Hernández, J. M. González-Buitrago, and J. L. Munoz-Bellido. 2010. Direct identification of urinary tract pathogens from urine samples by matrix-assisted laser desorption ionization-time of flight mass spectrometry. J. Clin. Microbiol. 48:2110-2115.

Ferreira, L., F. Sánchez-Juanes, I. Porras-Guerra, M. I. Garcia-Garcia, J. E. Garcia-Sanchez, J. M. González-Buitrago, and J. L. MunozBellido. 2011. Microorganisms direct identification from blood culture by matrix assisted laser desorption/ionization time-of-flight mass spectrometry. Clin. Microbiol. Infect. 17:546-551.

Gonçalves, J. L., T. Tomazi, J. R. Barreiro, P. A. Braga, C. R. Ferreira, J. P. Araújo Júnior, M. N. Eberlin, and M. V. dos Santos. 2014. Identification of Corynebacterium spp. isolated from bovine intra-mammary infections by matrix-assisted laser desorption ionization-time of flight mass spectrometry. Vet. Microbiol. 173:147-151.

Hovinen, M., and S. Pyörälä. 2011. Invited review: Udder health of dairy cows in automatic milking. J. Dairy Sci. 94:547-562.

Ilina, E. N., A. D. Borovskaya, M. M. Malakhova, V. A. Vereshchagin, A. A. Kubanova, A. N. Kruglov, T. S. Svistunova, A. O. Gazarian, T. Maier, M. Kostrzewa, and V. M. Govorun. 2009. Direct bacterial profiling by matrix-assisted laser desorption-ionization time-of-flight mass spectrometry for identification of pathogenic Neisseria. J. Mol. Diagn. 11:75-86.

Ilina, E. N., A. D. Borovskaya, M. V. Serebryakova, V. V. Chelysheva, K. T. Momynaliev, T. Maier, M. Kostrzewa, and V. M. Govorun. 2010. Application of matrix-assisted laser desorption/ionization time-of-flight mass spectrometry for the study of Helicobacter pylori. Rapid Commun. Mass Spectrom. 24:328-334.

Maier, T., G. Schwarz, and M. Kostrzewa. 2010. Microorganism Identification and Classification Based on MALDI-TOF MS Fingerprinting with MALDI Biotyper. Application Note. Bruker Daltonik GmbH, Bremen, Germany.

Malek dos Reis, C. B., J. R. Barreiro, J. F. Moreno, M. A. Porcionato, and M. V. Santos. 2011. Evaluation of somatic cell count thresholds to detect subclinical mastitis in Gyr cows. J. Dairy Sci. 94:4406-4412.

Moussaoui, W., B. Jaulhac, A. M. Hoffmann, B. Ludes, M. Kostrzewa, P. Riegel, and G. Prévost. 2010. Matrix-assisted laser desorption ionization time-of-flight mass spectrometry identifies $90 \%$ of bacteria directly from blood culture vials. Clin. Microbiol. Infect. 16:1631-1638.

Nagy, E., T. Maier, E. Urban, G. Terhes, and M. Kostrzewa. 2009. Species identification of clinical isolates of Bacteroides by matrixassisted laser-desorption/ionization time-of-flight mass spectrometry. Clin. Microbiol. Infect. 15:796-802.

Office International des Épizooties (OIE). 2010. The animal health and production compendium: Manual of diagnostic test and vaccines for terrestrial animals. Accessed Dec. 13, 2016. http://www.oie. int/en/international-standard-setting/terrestrial-manual/accessonline/.

Pankey, J. W., P. A. Drechsler, and E. E. Wildman. 1991. Mastitis prevalence in primigravid heifers at parturition. J. Dairy Sci. 74:1550-1552.

Pyörälä, S. 2003. Indicators of inflammation in the diagnosis of mastitis. Vet. Res. 34:565-578.

Rajendhran, J., and P. Gunasekaran. 2011. Microbial phylogeny and diversity: Small subunit ribosomal RNA sequence analysis and beyond. Microbiol. Res. 166:99-110.

Ryzhov, V., and C. Fenselau. 2001. Characterization of the protein subset desorbed by MALDI from whole bacterial cells. Anal Chem. 73:746-750.

Santos, M. V., Y. Ma, and D. M. Barbano. 2003. Effect of somatic cell count on proteolysis and lipolysis in pasteurized fluid milk during shelf-life storage. J. Dairy Sci. 86:2491-2503.

Segawa, S., S. Sawai, S. Murata, M. Nishimura, M. Beppu, K. Sogawa, M. Watanabe, M. Satoh, T. Matsutani, M. Kobayashi, Y. Iwadate, S. Kuwabara, N. Saeki, and F. Nomura. 2014. Direct application of MALDI-TOF mass spectrometry to cerebrospinal fluid for rapid pathogen identification in a patient with bacterial meningitis. Clin. Chim. Acta 435:59-61.

Seng, P., M. Drancourt, F. Gouriet, B. La Scola, P. E. Fournier, J. M. Rolain, and D. Raoult. 2009. Ongoing revolution in bacteriology: Routine identification of bacteria by matrix-assisted laser desorption ionization time-of-flight mass spectrometry. Clin. Infect. Dis. 49:543-551.

Seng, P., J. M. Rolain, P. E. Fournier, B. La Scola, M. Drancourt, and D. Raoult. 2010. MALDI-TOF-mass spectrometry applications in clinical microbiology. Future Microbiol. 5:1733-1754.

Stevenson, L. G., S. K. Drake, and P. R. Murray. 2010. Rapid identification of bacteria in positive $\mathrm{BC}$ broths by matrix-assisted laser desorption ionization time of flight mass spectrometry. J. Clin. Microbiol. 48:444-447.

Szabados, F., M. Michels, M. Kaase, and S. Gatermann. 2011. The sensitivity of direct identification from positive BacT/ALERT (BioMérieux) blood culture bottles by matrix-assisted laser desorption ionization time-of-flight mass spectrometry is low. Clin. Microbiol. Infect. 17:192-195.

Tomazi, T., J. L. Goncalves, J. R. Barreiro, P. A. C. Braga, L. F. P. E. Silva, M. N. Eberlin, and M. V. Santos. 2014. Identification of coagulase-negative staphylococci from bovine intra-mammary infection by matrix-assisted laser desorption ionization-time of flight mass spectrometry. J. Clin. Microbiol. 52:1658-1663.

Viguier, C., S. Arora, N. Gilmartin, and K. Welbeck. 2009. Mastitis detection: Current trends and future perspectives. Trends Biotechnol. 27:486-493. 